\title{
Abnormal Development of the Retinogeniculate Projection in Siamese Cats ${ }^{1}$
}

\author{
MICHEL KLIOT ${ }^{2}$ AND CARLA J. SHATZ \\ Department of Neurobiology, Stanford University School of Medicine, Stanford, California 94305
}

\begin{abstract}
In the visual system of Siamese cats, the lateral geniculate nucleus (LGN) receives an abnormally large projection from the contralateral eye and a correspondingly reduced projection from the ipsilateral eye. In order to determine how this abnormal pattern of retinal input arises, the prenatal development of the retinogeniculate projection was studied in Siamese cats using the anterograde transport of intraocularly injected $\left[{ }^{3} \mathrm{H}\right]$ leucine and horseradish peroxidase. Labeled axons from the ipsilateral eye can be detected in the optic tract by embryonic day 30 (E30; gestation is 65 days), several days later than found in normally pigmented animals. The ipsilateral projection is not only apparently delayed but also is reduced in size as compared with normal animals, and this reduction persists throughout development, indicating that the Siamese mutation acts to misdirect growing optic axons to the contralateral side of the brain as originally proposed (Guillery, R. W. (1969) Brain Res. 14: 739-741).
\end{abstract}

The effect of an altered retinal projection on the ingrowth and segregation of retinal fibers to the LGN was also examined. In Siamese fetuses, not until E41 can significant label be seen within the ipsilateral LGN as compared to E35 in normally pigmented fetuses. As in normal animals, in Siamese fetuses, also, the labeled retinogeniculate afferents from the two eyes initially overlap within regions of the LGN before segregating into layers. However, measurements of the area occupied by labeled afferents from the ipsilateral and contralateral eyes indicate that maximum overlap of the two sets of afferents, although close to normal in amount, does not occur until about E51-again several days later than in normally pigmented animals (E47).

The time course of segregation is also altered in Siamese cats. The onset of segregation, as signaled by the removal of contralateral eye afferents from territory destined for the ipsilateral eye and by the restriction of ipsilateral eye afferents, does not occur until about E51 in Siamese cats as compared with E47 in normally pigmented animals. Despite this delay in onset, the final segregation of the two sets of afferents in Siamese cats reaches adult-like levels at about the normal time. Thus, the misrouting of axons at the optic

Received November 1, 1984; Revised March 4, 1985;

Accepted March 4, 1985

\footnotetext{
${ }^{1}$ We wish to thank Drs. R. W. Guillery and J. Silver, and D. W. Sretavan, for their helpful criticisms of the manuscript, and Cecele Thomas for her secretarial assistance. This research was supported by National Institutes of Health Grant EY 02858 to C. J. S. and Training Grant HD 07244 to M. K.

${ }^{2}$ Current address: Neurological Institute, Columbia Presbyterian Medical Center, New York, NY 10032

${ }^{3}$ To whom reprint requests should be sent.
}

chiasm in Siamese cats not only alters the final pattern of innervation from the two eyes within the LGN, but also delays the onset and shortens the total duration of segregation itself.

Little is known about the developmental mechanisms that give rise to the laterality of retinal ganglion cell projections. Genetic mutations affecting the nervous system provide insight into some of the mechanisms underlying normal development (for review see Stent, 1981). For example, mutations at several genetic loci that produce a congenital lack or reduction in ocular melanin are found in association with an abnormal optic projection in a number of different mammalian species (Lund, 1965; Guillery, 1969, 1971; Guillery and Kaas, 1971; Guillery et al., 1973, 1975, 1979, 1984; Creel and Giolli, 1972; Sanderson ct al., 1974; LaVail et al., 1978). One of the best studied examples is the retinogeniculate projection of adult Siamese cats in which an allele at the albino locus results in an abnormally large crossed and correspondingly reduced uncrossed projection (Guillery, 1969; Guillery and Kaas, 1971; Shatz, 1977; Cooper and Pettigrew, 1979b; Leventhal, 1982; Murakami et al., 1982). Figure 1 illustrates this difference both schematically and with darkfield photographs showing the actual pattern of labeled retinal afferents within the lateral geniculate nucleus (LGN) of an adult normally pigmented (Fig. $1 A$ ) and Siamese (Fig. 1B) cat.

In normal adult cats the retinal ganglion cells within each eye are sharply divided into two halves by virtue of their axonal projection to the LGN (Cooper and Pettigrew, 1979a; Illing and Wassle, 1981). As shown in Figure $1 A$, the axons from retinal ganglion cells in the nasal half of each eye cross in the optic chiasm and terminate in layers $A, C$, and $C 2$ of the contralateral LGN. Axons from retinal ganglion cells in the temporal half of each eye do not cross but project instead to the ipsilateral LGN where they terminate in the alternate $\mathrm{A} 1$ and $\mathrm{C} 1$ layers (Guillery, 1970; Hickey and Guillery, 1974).

In contrast, the nasotemporal division in adult Siamese cats is abnormal, as shown in Figure $1 B$ (Kaas and Guillery, 1973; Kirk, 1976; Stone et al., 1978a, b; Cooper and Pettigrew, 1979b; Leventhal, 1982; Murakami et al., 1982). The contralateral projection to the LGN consists of axons from retinal ganglion cells in the nasal retina, as usual, plus an abnormal component from the temporal retina which projects to portions of layer $A 1$ ( $a b A 1$, the abnormal segment of layer $A 1$ ) and layer $C 1$. A reduced number of the remaining retinal ganglion cells in the temporal half of the retina send axons to the ipsilateral LGN, where they are confined to several small patches in layer A1 (mnA1, medial normal segment of A1; InA1, lateral normal segment of $A 1$ ) and in layer $C 1$ (see Guillery, 1969, for nomenclature).

In order to understand how the abnormal retinogeniculate projection arises in Siamese cats, we have examined and compared the time course and pattern of development of this pathway with that occurring in normally pigmented animals. In an initial study (Shatz and Kliot, 1982), we found that the size of the ipsilateral projection 

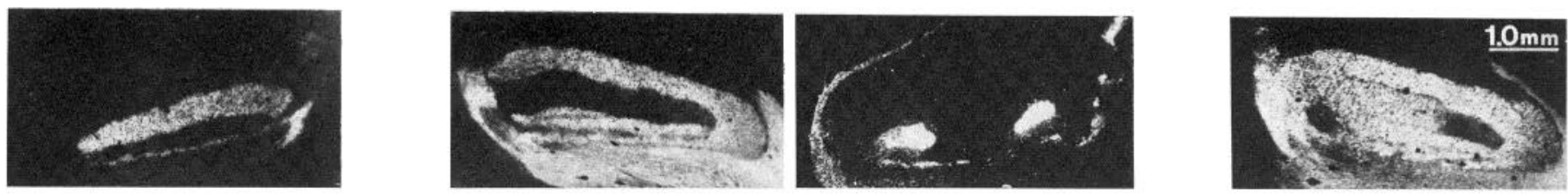

A

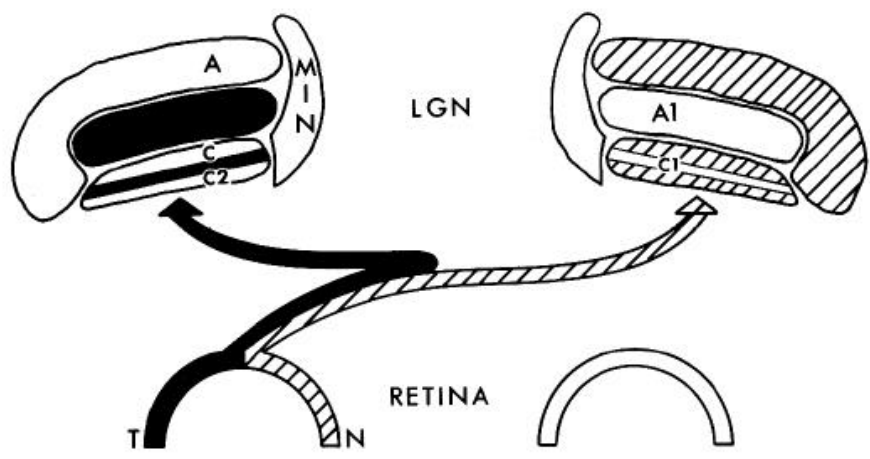

B

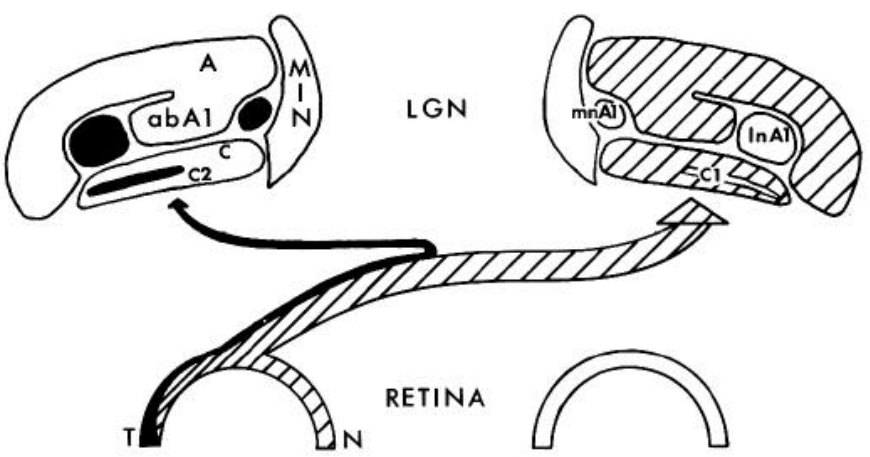

Figure 1. A schematic diagram to illustrate the retinogeniculate projection in normally pigmented $(A)$ and Siamese $(B)$ adult cats. Only the projection from the left eye is shown for simplicity. $A$, Normally, axons from retinal ganglion cells in the nasal half of each retina (hatched area labeled $N$ ) cross at the chiasm and project to layers A, C, and C2 of the contralateral LGN. Those in the temporal half (black area labeled $T$ ) project ipsilaterally to the A1 and C1 layers. $B$, In the Siamese cat, the LGN receives an abnormally large projection from the contralateral retina (right LGN: hatched area), consisting of additional fibers from the temporal retina (hatched area) that innervate portions of layers A1 (abA1: the abnormal segment of layer A1) and C1. There is a correspondingly reduced projection from the ipsilateral retina (left LGN: black areas) that terminates in several small patches medially (mnA1: the medial normal segment of $\mathrm{A} 1)$ and laterally (InA1: the lateral normal segment of $\mathrm{A} 1$ ) in layer $\mathrm{A} 1$ and in layer $\mathrm{C} 1$. The projection to the medial interlaminar nucleus (MIN) is similarly affected in Siamese cats but is not shown here. The photographs above each schematic LGN in $A$ and $B$ are actual autoradiographs of coronal sections through the midportion of the LGN in normal $(A)$ and Siamese $(B)$ cats shown in darkfield optics to illustrate the pattern of the retinogeniculate projection following an injection of $\left[{ }^{3} \mathrm{H}\right]$ leucine into the left eye. Regions containing radioactive label appear white.

was reduced within the optic tract and LGN throughout development, suggesting that the Siamese mutation indeed acts to misdirect growing retinal ganglion cell axons at the optic chiasm. Here, we are especially interested in the effect that this altered retinal projection has on the pattern of ingrowth and time course of segregation of retinal afferents from the two eyes within the LGN. The results indicate that the time of arrival and balance of input from the two eyes to the LGN can influence these processes.

\section{Materials and Methods}

In the present report a total of 29 Siamese cats were studied: 21 fetuses of known gestational age, 7 newborns, and 1 adult. These results are compared to those from a previous study (Shatz, 1983) involving 64 normal fetuses, 9 normal newborns, and 1 normal adult cat. Fetuses were obtained from our own pure-bred Siamese colony. Mature Siamese females found to be in estrus were mated with an experienced Siamese male for 24 to $48 \mathrm{hr}$. The actual gestational age of a fetus may therefore vary by as much as 48 hr. The first day of breeding was arbitrarily designated as embryonic day 0 (EO) and birth was designated as postnatal day $0(P 0)$. (The average gestation period is 65 days.) The crown-rump length of each fetus was routinely measured and compared with normally pigmented animals of the same gestational age, as shown in Figure 2: at least grossly, the development of the Siamese fetuses studied here (Fig. 2, black dots) is similar to that of normals (Fig. 2, solid line).

In order to make eye injections, the fetal surgery techniques of Rakic (1976), modified for the cat (Shatz, 1983), were used. Pregnant females were pre-anesthetized with a mixture of ketamine $(20 \mathrm{mg} / \mathrm{kg})$ and acepromazine $(0.2 \mathrm{mg} / \mathrm{kg})$ followed by an intramuscular injection of atropine sulfate $(0.5 \mathrm{mg} / \mathrm{kg})$. Cats were then intubated and anesthesia was maintained with a mixture of halothane (0.5 to $1.0 \%$ ) with nitrous oxide and oxygen in a $1: 2$ ratio. Expired $\mathrm{pCO}_{2}$ was monitored continuously and a $5 \%$ dextrose Ringer's solution was infused intravenously throughout the surgery.

Using sterile technique, caesarian sections were made to expose the fetal head. Uterine contractions were controlled with IV Brethine $(0.03 \mathrm{mg} / \mathrm{kg})$ and the topical application of $5 \%$ cyclaine periodically. Intraocular injections of $\left[{ }^{3} \mathrm{H}\right]$ leucine (40 to $60 \mathrm{Ci} / \mathrm{mmol}$ ) and/or horseradish peroxidase (HRP) (Boehringer-Mannheim type 1) were made into the vitreous body of the eye. For the HRP injection a $40 \%$ solution of HRP in $1 \%$ lysophosphatidyl choline (Sigma type 1) was used (see Table I in Shatz, 1983, for injection amounts). in 21 of the 29 animals, one eye was injected with HRP and the other with $\left[{ }^{3} \mathrm{H}\right]$ leucine in order to maximize the chances of obtaining successful injections. (See Table I for specific details.)

Following the eye injections, fetuses were returned to the uterus for a 24 hr postinjection survival period. Then they were once again delivered by caesarian section and perfused intracardially with $0.1 \mathrm{M}$ sodium phosphate buffer $(\mathrm{pH} 7.3)$. Animals receiving both $\left[{ }^{3} \mathrm{H}\right]$ leucine and HRP eye injections were perfused with $1 \%$ paraformaldehyde, $1.25 \%$ glutaraldehyde, and $5 \%$ sucrose in $0.1 \mathrm{M}$ phosphate buffer. Animals injected with $\left[{ }^{3} \mathrm{H}\right]$ leucine alone were perfused with $4 \%$ paraformaldehyde, $5 \%$ sucrose in $0.1 \mathrm{M}$ phosphate

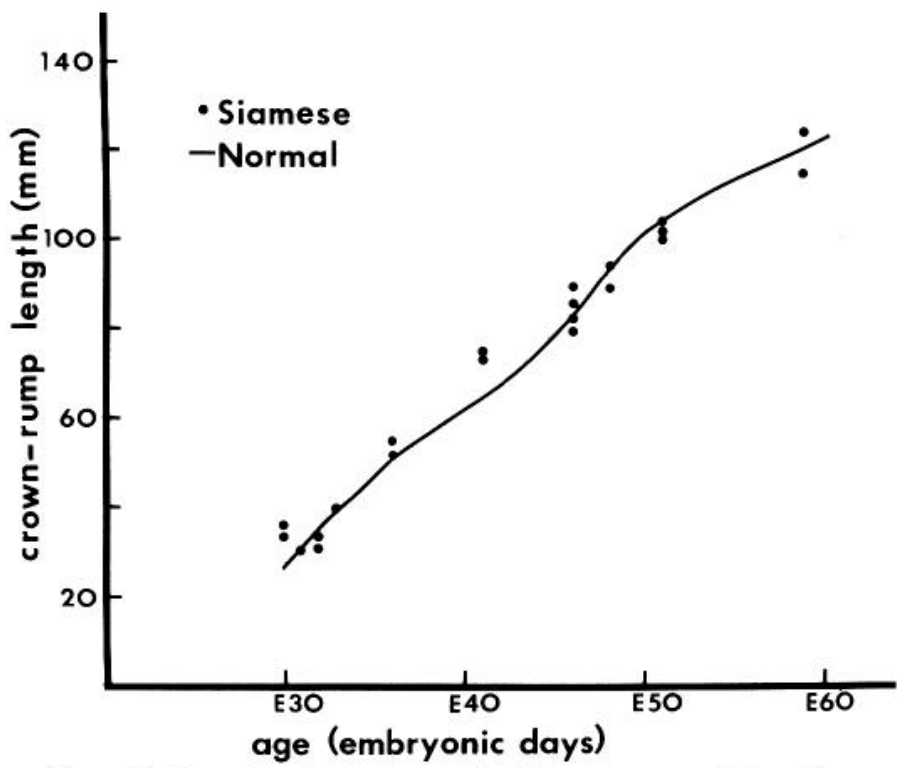

Figure 2. A graph of crown-rump length versus age of the Siamese fetuses used in this study. Each dot represents an individual animal. For comparison, the solid line represents averaged values for normally pigmented fetuses taken from Shatz (1983). Note that the crown-rump lengths of Siamese fetuses studied here are very similar to those of normally pigmented fetuses of the same age. 
TABLE I

Animals studied

\begin{tabular}{|c|c|c|}
\hline \multirow{2}{*}{ Age at Perfusion } & \multicolumn{2}{|c|}{ Number Receiving intraocular injections of: } \\
\hline & {$\left[{ }^{3} \mathrm{H}\right]$ Leucine only ${ }^{a}$} & {$\left[{ }^{3} \mathrm{H}\right]$ Leucine + HRP ${ }^{b}$} \\
\hline $\mathrm{E} 30$ & 1 & 1 \\
\hline E31 & & 1 \\
\hline E32 & 1 & 1 \\
\hline E33 & 1 & \\
\hline E36 & & 2 \\
\hline E41 & 1 & 1 \\
\hline E46 & 1 & 3 \\
\hline E48 & & 2 \\
\hline E51 & 1 & 2 \\
\hline E59 & 1 & 1 \\
\hline P1 & & 1 \\
\hline P2 & & 5 \\
\hline P4 & & 1 \\
\hline Adult & 1 & \\
\hline
\end{tabular}

\footnotetext{
a One eye only was injected.
}

${ }^{b}$ One eye was injected with $\left[{ }^{3} \mathrm{H}\right]$ leucine, the other with HRP.

buffer. The majority of fetal and newborn brains were blocked for sectioning in the horizontal plane since this plane has been shown (Shatz, 1983) to best reveal the laminae in the developing LGN. The adult brain was blocked in the standard coronal plane.

The brains of animals injected with only $\left[{ }^{3} \mathrm{H}\right]$ leucine wore frozen sectioned at $20 \mu \mathrm{m}$ following immersion in $4 \%$ paraformaldehyde, $20 \%$ sucrose. Those to be processed also for HRP histochemistry were rapidly embedded in gelatin alburrin and 50- $\mu$ rn sections were cul on a Vibratome. A series of alternate sections was then reacted using the tetramethylbenzidine protoco of Mesulam (1976) modified slightly to reduce tissue shrinkage (Shatz, 1983). Finally, sections were counterstained rapidly with neutral red. Autoradiography was performed on a separate series of sections that were dipped in Kodak NTB-2 emulsion, exposed for 1 to 3 weeks, and developed in Kodak D19. These sections were lightly counterstained with cresyl violet.

Changes in the pattern of the retinogeniculate projection during initial ingrowth, overlap, and subsequent segregation within the LGN were represented graphically by measuring the percentage of LGN area occupied by either radioactive label or HRP reaction product that was measured in a series of horizontal sections (about six per animal) (coronal in the adult), taken through the central two-thirds of the nucleus. Measurements were not made at the two poles of the LGN because the plane of section is not perpendicular to the plane of the (future) layers, making measurements difficult (see also Shatz, 1983). Measurements of area were made using a digitizing pad connected to an Apple computer. The percentage of ipsilateral and contralateral LGN containing either radioactive label or HRP (but not both) was calculated: the total area of the nucleus containing label was divided by the total cross-sectional area of the nucleus. In addition, the percentage of overlap, reflecting the amount of nucleus shared by the afferents from both eyes, was calculated: $\%$ overlap $=(\%$ of ipsilateral label $+\%$ of contralateral label) $-100 \%$. The histological borders of the nucleus were drawn in brightfield optics using a camera lucida attachment. (In animals E41 and younger the medial border of the nucleus is ill-defined and was therefore taken to coincide with the medial border of label in the contralatera LGN; see Shatz, 1983, for further justification.) At every age, camera lucida drawings of labeled portions of each nucleus were made using darkfield illumination. On the side ipsilateral to an eye injection all labeled regions judged to be above background were included. On the contralateral side labeled afferents initially occupy the entire extent of the LGN. As soon as regions with reduced density of grains could be identified they were excluded from the portion considered to be labeled. The use of slightly different criteria for the analysis of labeling on the two sides was intentional and, if anything tended to minimize differences in the time course of segregation for normal and Siamese cats.

\section{Results}

Retinogeniculate projection in Siamese cats at birth. By birth the retinogeniculate projection in Siamese cats closely resembles that seen in the adult. This is shown in Figure 3 , which is composed of darkfield autoradiographs showing the pattern of label at four different levels through the LGN of a postnatal day 2 (P2) Siamese cat.
As shown in Figure $3, B$ and $C$, labeled fibers extend throughout most of the contralateral LGN, including a portion of the $\wedge 1$ layers (abA1), but is excluded from several small patches which are labeled on the ipsilateral side and correspond to the medial (mnA1) and lateral $(\ln A 1)$ normal segments of $A 1$ as well as portions of $\mathrm{C} 1$. Both the medial and lateral normal segments are prominent in the midportion of the LGN (Fig. $3, B$ and $C$ ). They fuse to form a single labeled region in the ventral portion of the LGN (Fig. $3 A$ ), and only the lateral normal segment extends into the dorsal portion of the LGN (Fig. 3D). If one takes into account the postnatal $90^{\circ}$ rotation of the LGN which occurs in the sagittal plane and shifts the ventral pole anterior and the dorsal pole posterior (Kalil, 1978), then the pattern of labeling through the LGN is virtually identical to that found in the adult Siamese cat (see Fig. 7 in Shatz, 1977, for comparison with adult).

At birth the labeled retinal afferents are largely excluded from the interlaminar zone that separates layer $A$ from the lateral portion of layer At (abA1, Fig. 3, B and $C$ ). In cresyl violet-stained sections this interlaminar zone can be found to be relatively cell free as shown in Figure $4 A$. The extent of this zone differs from that found in normally pigmented newborn and adult cats in that it does not extend as far medially as the border between the LGN and the medial interlaminar nucleus (see Fig. $7 B$ in Shatz, 1983, for comparison with normal newborn). This is because the medial portions of layers $A$ and $A 1$ (Fig. $4 A$ to the right of arrows) remain fused, a characteristic feature of the projection seen in many "Boston" Siamese cats and one that often distinguishes it from the Midwestern variety (Kaas and Guillery, 1973; Shatz, 1977). Earlier, at E59, an interlaminar zone is not obvious in the Siamese fetus (Fig. 4B) even though it could be seen in the E60 normal fetus (Shatz, 1983, Fig. 9). At even earlier stages of development (Fig. 4, $C$ and $D$ ) the nucleus is histologically indistinguishable from that seen in normal fetuses of the same age (Shatz, 1983). Thus, the abnormal pattern of cellular lamination found in adult Siamese cats is not evident until close to the completion of the abnormal pattern of retinogeniculate afferent segregation. Furthermore, since the retinogeniculate projection is adult-like at birth, it was necessary to perform the prenatal study described below.

Early development of the optic projection in normal and Siamese fetuses. In a previous study (Shatz and Kliot, 1982) we found that in Siamese fetuses the ipsilateral projection is reduced within the optic tract even before the first retinal afferents reach the vicinity of the developing LGN. Here we show further that there is also an apparent delay in the growth of ipsilateral fibers. Figure 5 shows camera lucida drawings of horizontal scctions through the brains of very young normal and Siamese fetuses to illustrate the location of anterogradely transported label within the optic tracts (Fig. 5, arrows) following eye injections: the distance (dorsalward) of each section from the optic chiasm is written beneath each drawing. In an E30 normal fetus, labeled retinal fibers can be detected by our methods as far as the anlage of the LGN on both sides (Fig. 5, E3ON-2.2 $\mathrm{mm}$ from the chiasm). In a Siamese fetus of the same age, however, labeled ipsilateral retinal fibers can be detected only as far as a point midway between the optic chiasm and LGN anlage (Fig. 5, E30S$1.2 \mathrm{~mm}$ ) despite the presence of a contralateral projection that extends as far as that found in the E30 normal fetus (Fig. 5, E30S$2.2 \mathrm{~mm}$ ). One day later, ipsilateral fibers can be found further dorsally (Fig. 5, $E 31 \mathrm{~S}-1.8 \mathrm{~mm}$ ), but label is still short of the LGN anlage even though the contralateral projection has further increased there (Fig. 5, E31S-2.6 mm). Thus, in Siamese fetuses not only is the early ipsilateral projection reduced in quantity, but it is apparently also delayed in its arrival at, and subsequent invasion of, the LGN.

The size of the ipsilateral projection is reduced within the optic tract throughout development, even after the afferents have invaded the L GN as shown in Figure 6. Here, the amount of label in the optic tracts of normal and Siamese cats following eye injections at several different ages is compared in a series of autoradiographs. At each embryonic age the amount of label in the ipsilateral tract of Siamese fetuses is markedly reduced as compared to similarly aged normal 
Figure 3. Autoradiographs (darkfield optics) of horizontal sections taken at four different levels from ventral $(A)$ to dorsal $(D)$ to illustrate the pattern of the ipsilateral (ipsi.) and contralateral (contra.) retinogeniculate projection in a P2 Siamese cat following an intraocular injection of $\left[{ }^{3} \mathrm{H}\right]$ leucine $24 \mathrm{hr}$ earlier. White lines delineate the border of the LGN on the ipsilateral side as determined from an adjacent cresyl violetstained section. InA1, lateral normal segment of $A 1 ; m n A 1$, medial normal segment of $A 1$; $M I N$, medial interlaminar nucleus; $a b A 1$, abnormal segment of layer $A 1$; OT, optic tract. Note that the pattern of the retinogeniculate projection at this age is remarkably adult-like (ct. Fig. 1).
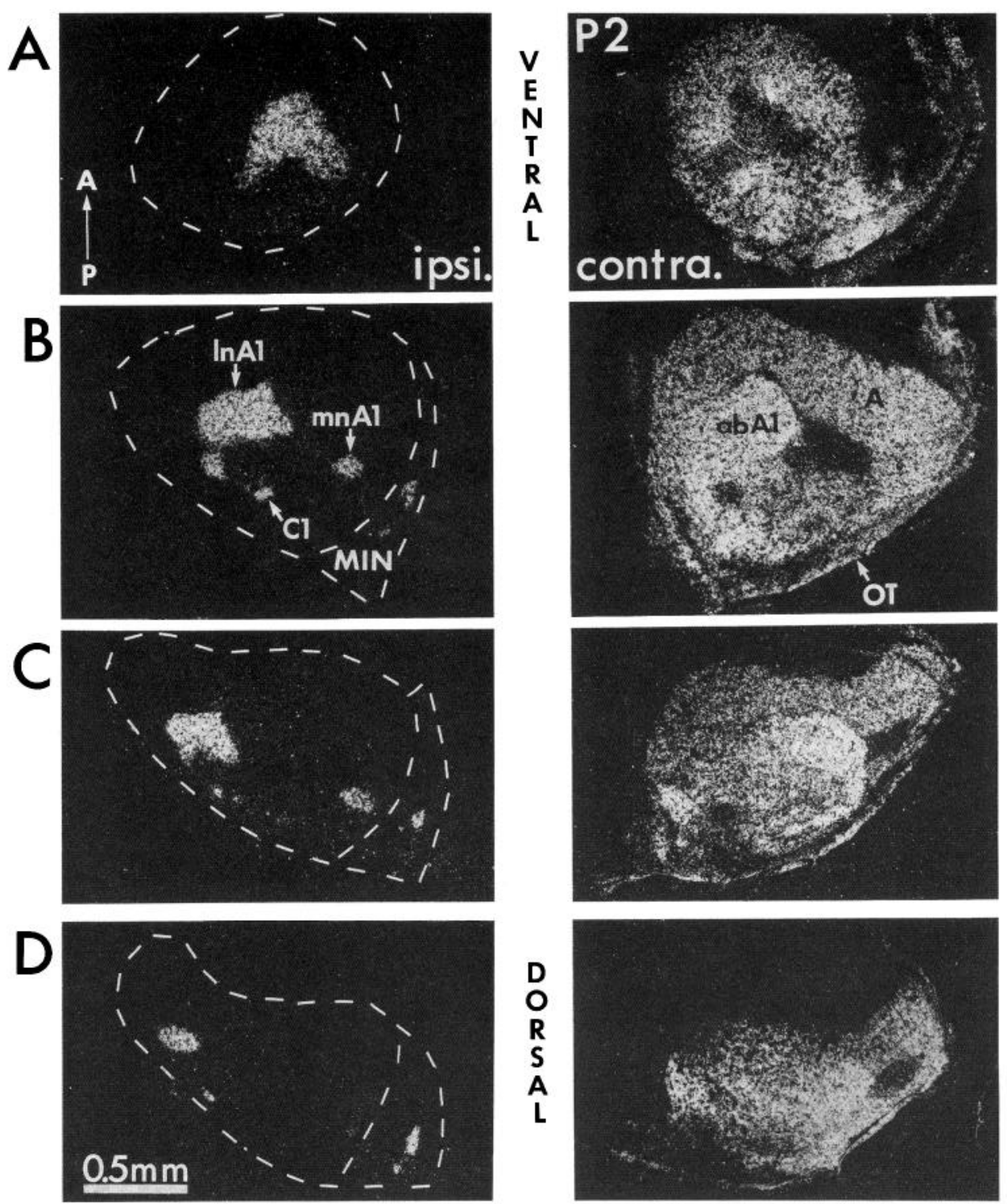

fetuses. (Brightfield optics were used here to better illustrate this difference. In fact, label can be seen in the ipsilateral optic tract of the Siamese animals with darkfield optics.) Nevertheless, an equivalent amount of label is present in the contralateral tract in both varieties of cat. These findings support the hypothesis that the abnormal optic projection in Siamese cats arises from the misrouting of growing fibers at the optic chiasm.

Ingrowth and segregation of retinogeniculate afferents in Siamese cats. The chiasmatic misrouting of retinal fibers that occurs in Siamese fetuses provides the opportunity to study how a diminished ipsilateral and augmented contralateral retinal input to the LGN affects the pattern of afferent ingrowth and segregation. The pattern of growth of retinal afferents into the LGN of Siamese fetuses is shown in Figures 7 and 8. At E32 (Fig. 7A) an extremely faint ipsilateral projection can be detected in the optic tract adjacent to the LGN anlage (see Fig. 11 in Shatz, 1983, for comparison with E32 normal). The ipsilateral projection increases progressively and, by E41, retinal fibers have penetrated the posterior pole of the nucleus (Fig. 7D, arrow). By analogy with the normal adult and fetal LGN (Shatz, 1983), this portion of the nucleus is likely to receive retinal input from the central part of the retina, where ganglion cells are first generated (Kliot and Shatz, 1982; Walsh et al., 1983).

Throughout this period, the contralateral projection is always more extensive than the ipsilateral one. For example, at E32 (Fig. 7A), afferents from the contralateral eye are found not only in the optic tract, but also within a thin band in the nucleus proper. At later ages there is a progressive increase in the size of the contralateral projection until, by E41, the entire LGN is filled.

At later fetal ages (E46 to E59) the ipsilateral projection becomes more substantial, as shown in Figure 8. However, unlike the contralateral projection, it never fills the entire LGN. Rather, ipsilateral label is always nonuniform and eventually becomes restricted to several densely labeled patches (Fig. 8, C and D). Concurrent with this restriction in the extent of the ipsilateral projection is the appearance of gaps in which label is reduced on the contralateral side in corresponding regions of the LGN. The gaps are first evident by E51 (Fig. 8C) and become more pronounced by E59 (Fig. 8D).

To illustrate in greater detail the sequence of segregation of the ipsilateral projection, camera lucida drawings were made of the pattern of label seen in horizontal sections taken at four different levels through the LGN at E46, E48, E51, and E59 as shown in Figure 9. Black shading represents densely labeled and gray stippling represents more lightly labeled regions within the LGN. From the drawings it can be seen that at E46 dense ipsilateral label is present anterolaterally in only the two ventralmost sections of the nucleus. At E48 the ipsilateral projection has increased in extent and 

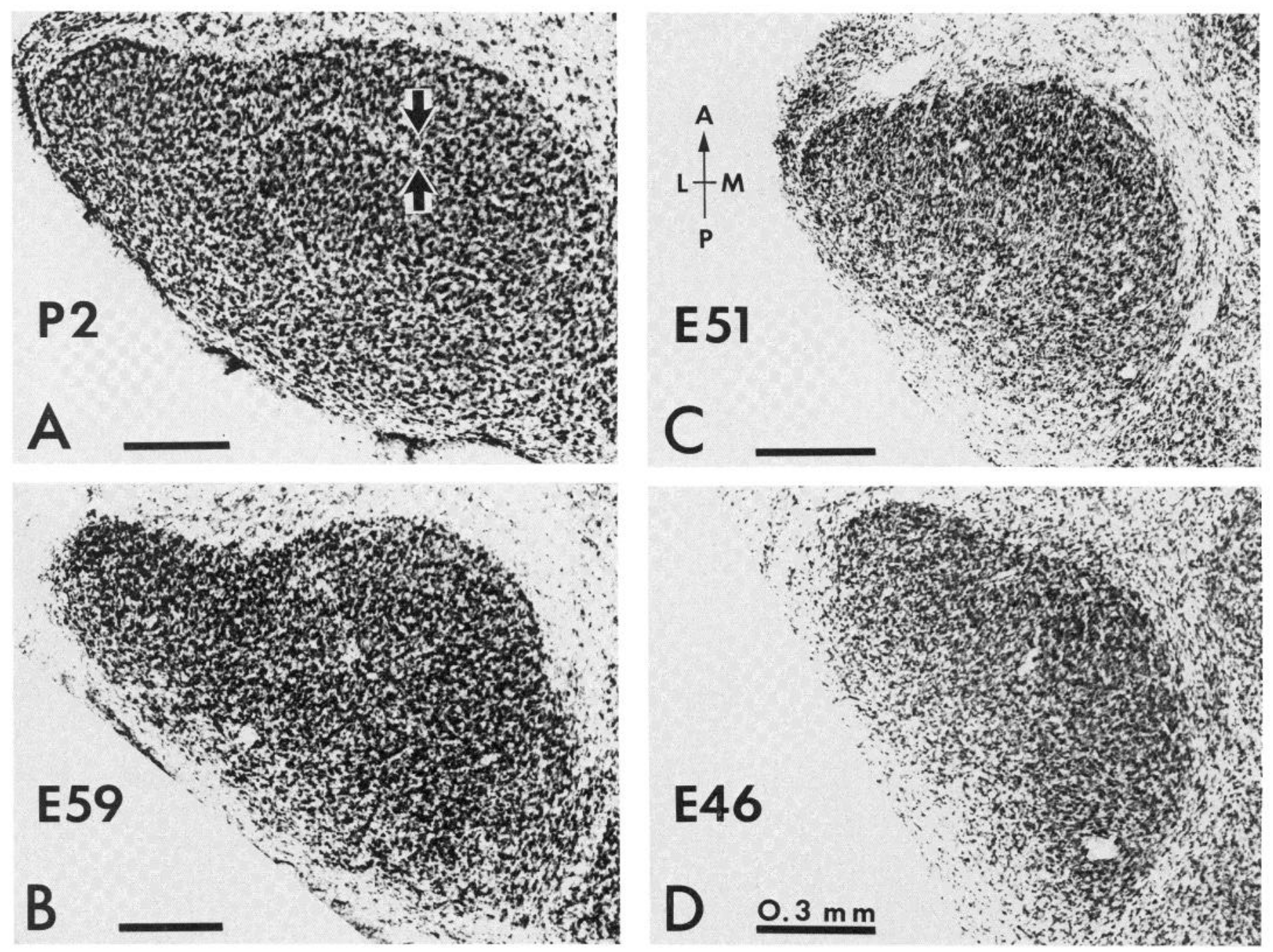

Figure 4. Photomicrographs (brightfield optics) of cresyl violet-stained horizontal sections to show the histological appearance of the LGN in Siamese cats during development. At P2 (A), an interlaminar zone separating the lateral portion of layer A1 from layer A is present (to the left of the arrows), but the medial portion of layers $\mathrm{A}$ and $\mathrm{A} 1$ are fused in the characteristic manner seen in the adult Siamese LGN (to the right of the arrows). In contrast, at progressively earlier stages of development no interlaminar zone can be identified: E59 (B), E51 (C), and E46 (D). Sections in $A$ and $B$ are $50 \mu \mathrm{m}$ thick and those in $C$ and $D$ are $20 \mu \mathrm{m}$ thick. $A$, anterior; $P$, posterior; $L$, lateral; $M$, medial. Each calibration bar is $0.3 \mathrm{~mm}$.

is still most densely labeled in what now resembles the lateral normal segment of future layer $\mathrm{A} 1$. This region of dense label now extends into the two dorsalmost sections. At E51 the ipsilateral projection occupies an even greater proportion of the nucleus and now two densely labeled regions can be seen throughout the dorsoventral extent of the nucleus: one is medial and the other is lateral. These correspond to the future medial and lateral normal segments of layer A1. A region of dense label can also be seen close to the optic tract in the ipsilateral LGN and probably is future layer C1. By E59 the ipsilateral projection is restricted to several heavily labeled regions that clearly resemble the medial and lateral normal segments of $A 1$, as well as portions of layer $\mathrm{C} 1$. In addition, the sparse label found in intervening regions at E51 is no longer present. Thus, as early as E46 ipsilateral retinal fibers demonstrate directed ingrowth into the LGN as shown by the dense labeling of only certain portions of future layer A1. During the next 2 weeks, an initially diffuse and patchy ipsilateral projection becomes concentrated into several densely labeled regions, while gaps begin to appear on the contralateral side. These observations indicate that the adult pattern of innervation is achieved both by the directed ingrowth and subsequent segregation of retinal afferents.

To examine the process of segregation in more detail, the per- centages of LGN area occupied by labeled fibers ipsilateral and contralateral to eye injections at different ages were determined as described under "Materials and Methods." The results are illustrated in Figure 10. The continuous lines are the results of this study on the Siamese cat. The dashed lines represent the averaged results from a previous study (Shatz, 1983) of development in normally pigmented cat fetuses. As shown in Figure 10, in Siamese fetuses the area occupied by the ipsilateral afferents increases gradually to reach a maximum by E51. This increase is followed by a rapid decline as the ipsilateral projection becomes restricted to the distinct patches seen by E59 (cf. Figs. $8 D$ and 9). The decline on the ipsilateral side is accompanied by a decrease in the area occupied by contralateral afferents that is due to the appearance of gaps in the contralateral labeling pattern at E51 (Fig. 8C).

When the Siamese results of Figure 10 are compared with those of normally pigmented animals, a number of significant differences become evident. First, there is an apparent delay and more gradual rate of ingrowth of the ipsilateral projection into the LGN of Siamese versus normal fetuses. For example, at E41 only $6 \%$ of the ipsilateral nucleus is labeled in Siamese fetuses compared to $35 \%$ at E40 in normal fetuses. In fact, at every age the percentage of ipsilateral label is always less in Siamese than in normal fetuses. The percent- 


\section{E 30N}

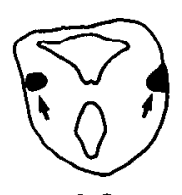

$0.2 \mathrm{~mm}$

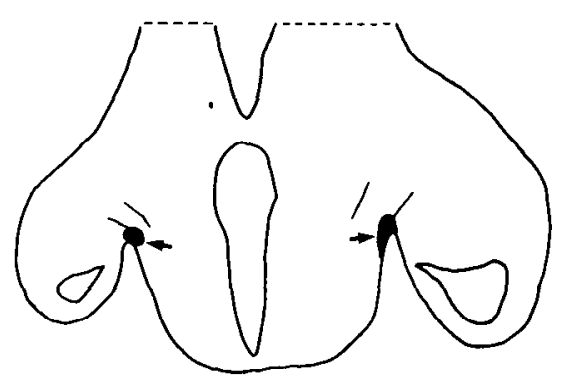

$1.2 \mathrm{~mm}$

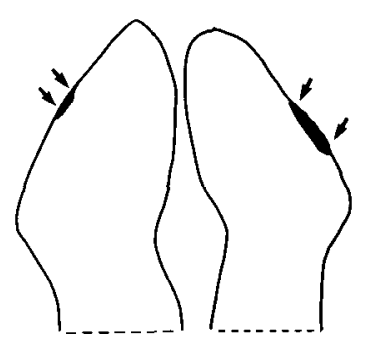

$2.2 \mathrm{~mm}$
E $30 \mathrm{~S}$
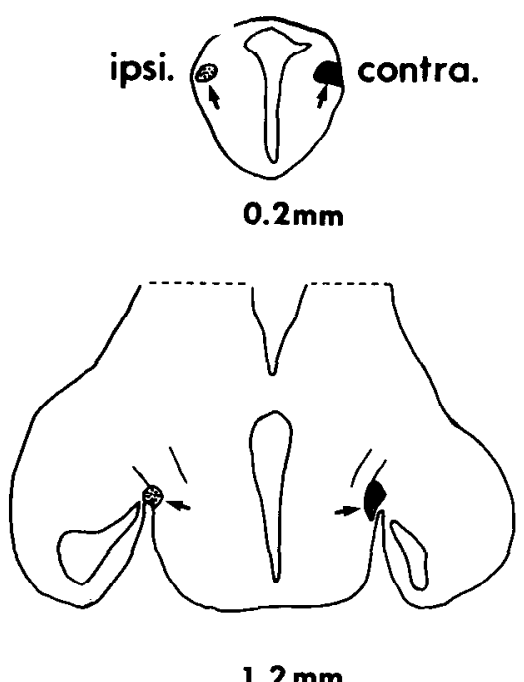

$1.2 \mathrm{~mm}$

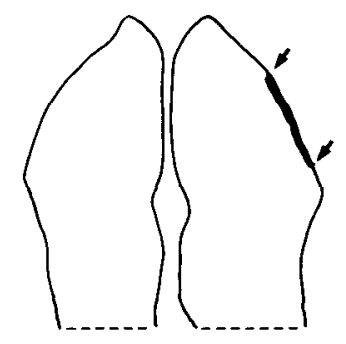

$2.2 \mathrm{~mm}$
E 315
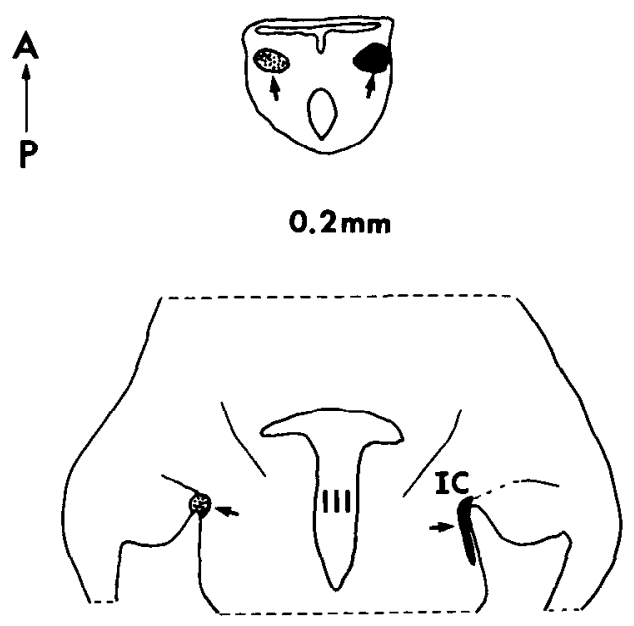

$1.8 \mathrm{~mm}$

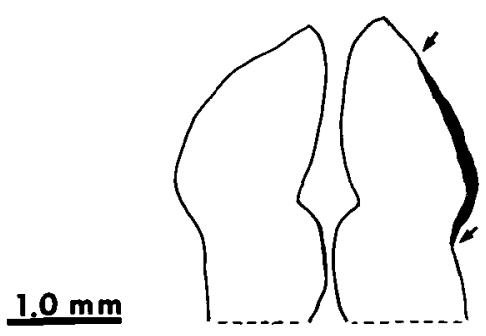

$2.6 \mathrm{~mm}$

Figure 5. A series of camera lucida drawings of autoradiographs to compare the extent of radioactive label present within the optic tracts (arrows) of very young normal $(E 3 O N)$ and Siamese (E3OS and E31S) fetuses, ipsilateral (ipsi.) and contralateral (contra.) to an eye injection. Black shading represents densely labeled and stippling, more lightly labeled regions. The distance of each horizontal section dorsal to the optic chiasm is written beneath each drawing. Sections in the bottom row are at the level of the anlage of the LGN. III, third ventricle; $I C$, internal capsule. Note that in the Siamese fetuses, the ipsilateral projection is reduced in amount and does not extend as far dorsally as in the normally pigmented fetus.

age of the LGN occupied by ipsilateral label reaches a maximum for normal animals on $E 47$, with an average value of $48 \%$ (range, 44 to $55 \%$ ). In contrast, in Siamese fetuses the percentage of label within the ipsilateral LGN reaches a peak later, on E51. Despite this delay, the average value of $40 \%$ (range, 38 to $42 \%$ ) is rather similar to that seen in normals. However, the subsequent reduction that occurs in the area occupied by the ipsilateral projection is more rapid and extensive in Siamese than in normal animals. Thus, by E59, only $5 \%$ of the LGN is occupied by ipsilateral afferents in Siamese cats, whereas in normal animals about $40 \%$ of the nucleus remains occupied. At birth, ipsilateral afferents occupy roughly $6 \%$ of the nucleus in Siamese cats as compared to $32 \%$ in normal animals, but in both varieties these percentages are close to their respective adult values (see Shatz, 1977, Table I; Shatz, 1983; Cooper and Pettigrew, 1979b).

Figure 10 also illustrates that the development of the contralateral projection differs in Siamese and normally pigmented animals. For example, in Siamese fetuses, the percentage of LGN area occupied by the contralateral projection does not begin to decrease until E51-about 4 days later than in normal fetuses, and values thereafter never fall to normal adult levels $(86 \%$ in adult Siamese cats versus $60 \%$ in normal adults).

The above results indicate that the time course of the process of segregation of retinogeniculate afferents from the two eyes differs in Siamese and normal fetuses. This process is described and compared more directly by plotting the percentage of LGN area shared by retinal afferents from both eyes (percentage of overlap) against gestational age, as shown in Figure 11. To do this, the percentage of overlap was calculated by adding together the percentage of areas occupied by ipsilateral and contralateral label as determined for each animal in Figure 10 and then subtracting $100 \%$. As shown in Figure 11, the period of time during which the two sets of afferents overlap each other is significantly different: it is reduced in Siamese cats. Nevertheless, it is noteworthy that the peak percentage of overlap does not differ significantly between the two varieties: for Siamese fetuses it is $40 \pm 3 \%$ at E51, whereas for normals it is $33 \pm 15 \%$ (Shatz, 1983) at E47. Finally, Figure 11 shows that overlap values in Siamese cats never fall to the negative values found in normally pigmented adult animals but ralter remain near $0 \%$ from birth onward. This difference is due to the abnormal laminar organization of the Siamese LGN. In normal postnatal animals, the interlaminar zones separating adjacent LGN layers from each other account for about $10 \%$ of the cross-sectional area of the nucleus but do not receive input from the retina; hence, the negative values (see Shatz, 1983). The same is true of Siamese cats, the difference being that the interlaminar zones are greatly reduced due to the persistent fusions between the medial portions of layers $A$ and A1 (Kaas and Guillery, 1973; Shatz, 1977). Thus, this analysis has revealed that not only the pattern but also the time course of segregation of retinal afferents within the LGN is abnormal in Siamese cats.

\section{Discussion}

This study has shown that the genetic mutation present in Siamese cats misdirects growing retinal ganglion cell axons at the optic chiasm during fetal development. As a consequence, the proportion 


\section{ipsi. \\ NORMAL}
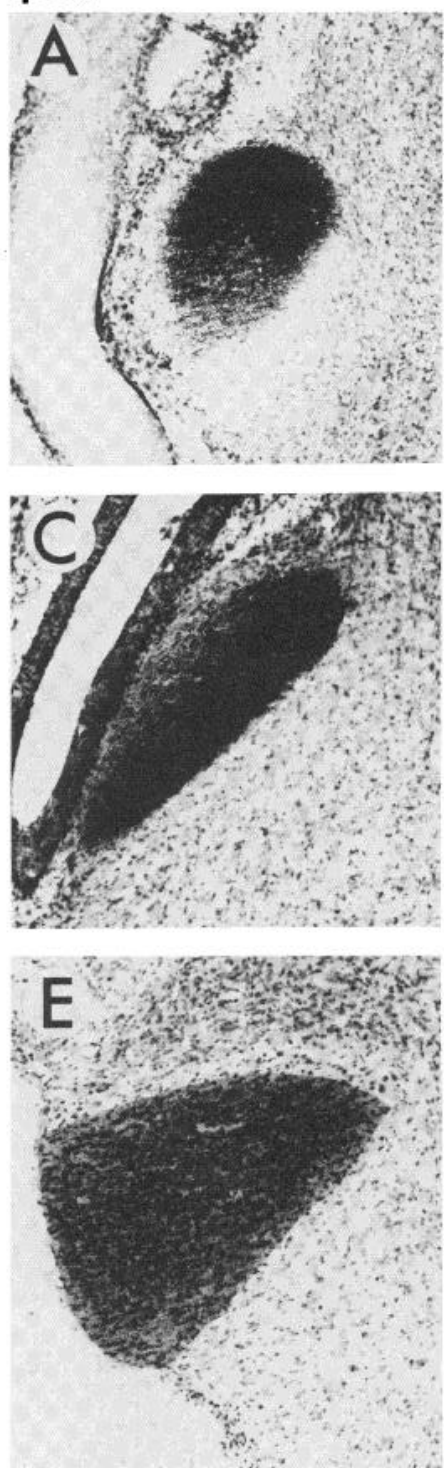
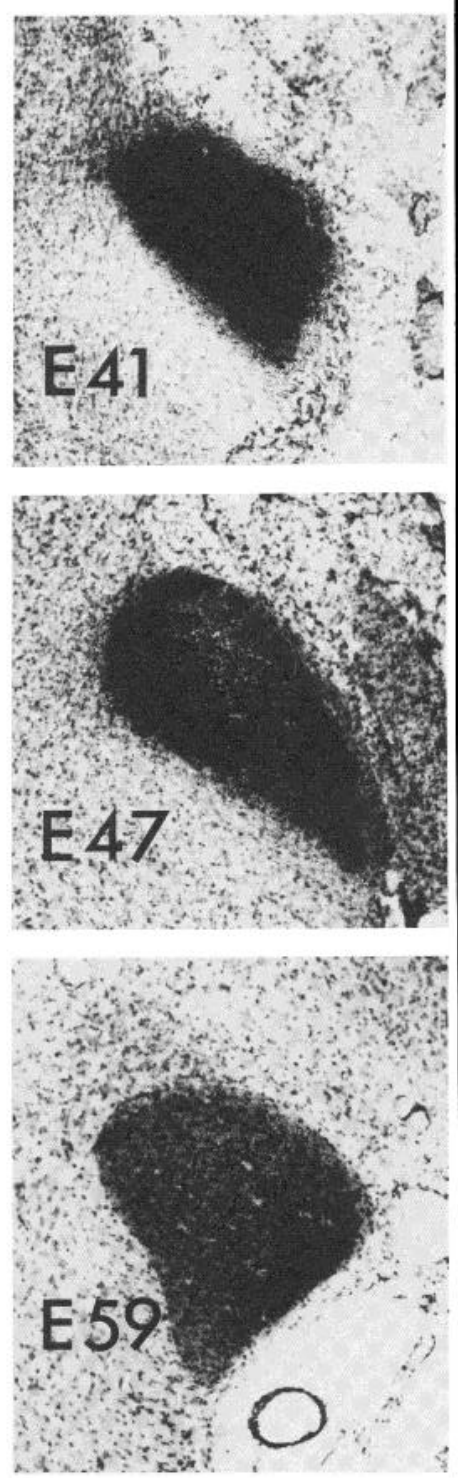

SIAMESE
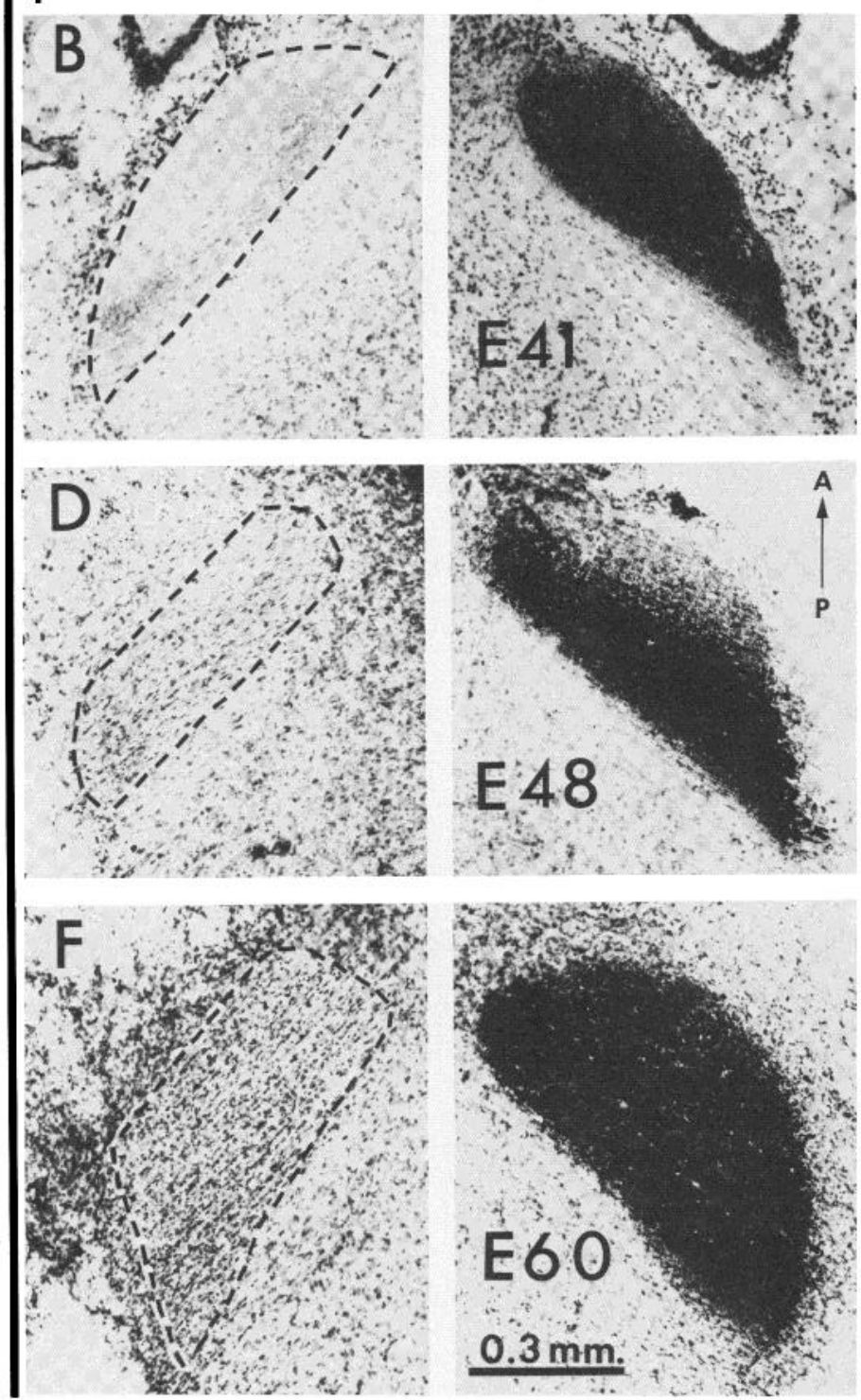

Figure 6. Autoradiographs of horizontal sections through the optic tracts counterstained with cresyl violet to compare the relative size of the ipsilateral (ipsi.) and contralateral (contra.) retinofugal projection in normal (left) and Siamese (right) fetuses at three embryonic ages: $A$ and $B, E 41 ; C$ and $D, E 47-$ E48; $E$ and $F, E 59-E 60$. All animals received intraocular injections of $\left[{ }^{3} \mathrm{H}\right]$ leucine; radioactive label within the optic tracts appears black in these brightfield photographs. Brightfield optics were chosen here to emphasize the disparity in the ipsilateral projection between Siamese and normal fetuses. (In darkfield optics, the ipsilateral optic tracts of all three Siamese fetuses appeared uniformly and substantially labeled.) Black dashed lines outline the ipsilateral optic tract of the Siamese fetuses. $A$, anterior; $P$, posterior. The calibration bar in $F$ applies to $A$ to $F$.

of crossed and uncrossed optic fibers is altered, giving rise to abnormalities both in the timing and the pattern of ingrowth and segregation within the LGN that can be distinguished from that found in normally pigmented animals throughout development. These observations suggest that the major effect of the genetic mutation is expressed at or before the level of the optic chiasm, as originally suggested by Guillery (1969), and that the alterations seen at the level of the LGN are a result of the consequent expanded contralateral and reduced and delayed ipsilateral input.

Chiasmatic misrouting of retinal fibers. A reduced ipsilateral projection is found throughout development in Siamese cats and therefore cannot be due only to a delay in the growth of the ipsilateral fibers. Rather, we believe that the reduction is due to the misrouting of axons at the optic chiasm. A similar persistent reduction in the size of the ipsilateral projection has also been observed in the developing albino ferret (Cucchiaro and Guillery, 1984). In contrast, however, is the finding in albino rats that a diminished ipsilateral projection emerges only secondarily following an elimination of axons that occurs after they have reached their targets (Land et al., 1981). Such a difference between species may reflect differences in the action of the mutant gene. Alternatively, it may reflect significant differences in the mechanisms underlying normal development. In both normal and albino rats numerous ectopic retinal ganglion cells initially project ipsilaterally and are subsequently eliminated (Land et al., 1981). In cats, however, the pattern of ganglion cell decussation is adult-like, at least as early as E44 (Lia et al., 1983). Thus, the large and precise ipsilateral projection found normally in higher mammals such as the cat, but not in rodents, may arise as a consequence of the greater degree of directed growth of axons during early development.

The initial events associated with the chiasmatic misrouting of ganglion cell axons are currently unknown; moreover, this study cannot contribute directly here because the youngest fetuses included were E30, several days after the first axons are known to reach the chiasm (J. Silver, M. Kliot, and C. J. Shatz, manuscript in preparation). For instance, it is not yet known whether the number 

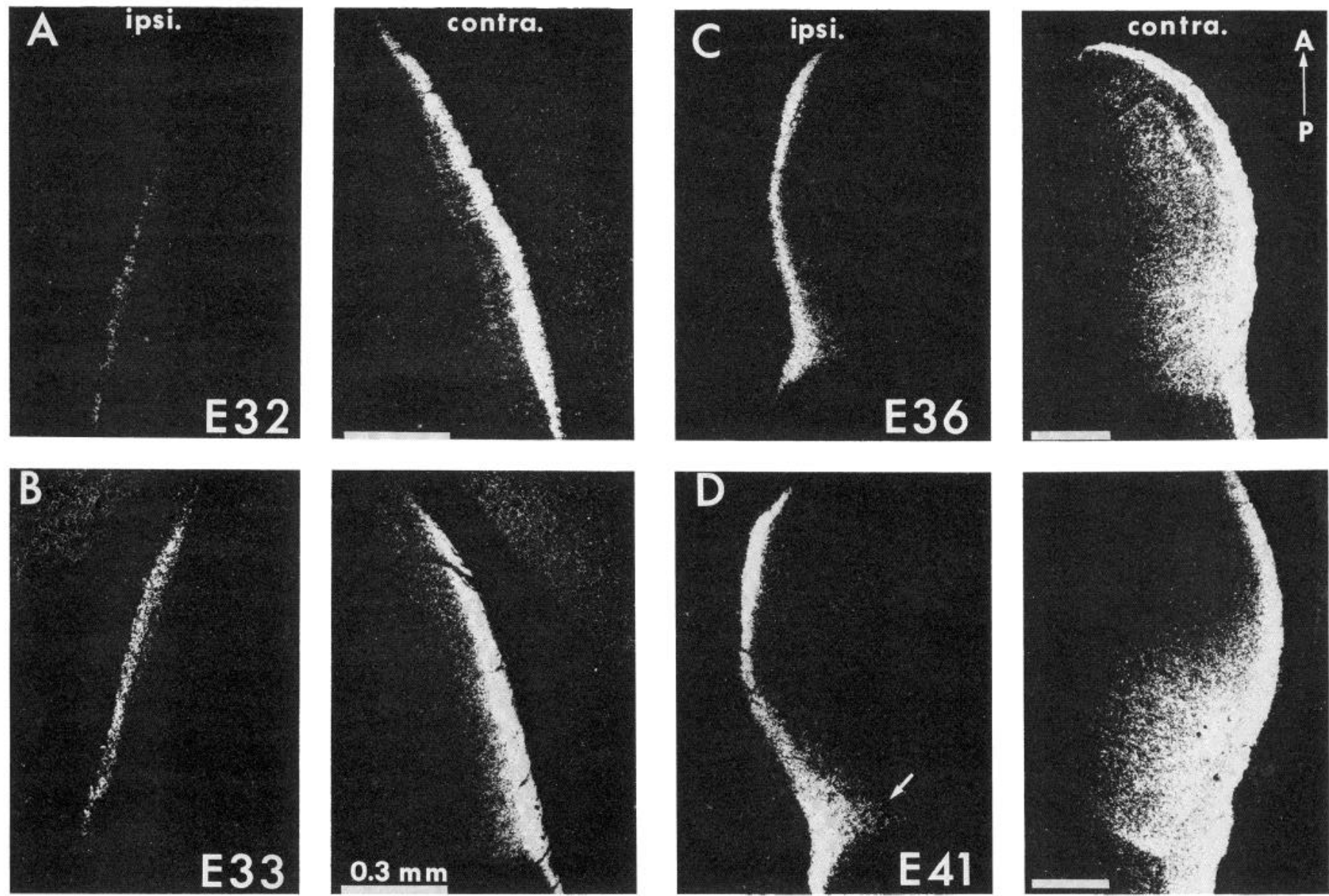

Figure 7. Darkfield autoradiographs of horizontal sections through the midportion of the LGN to show in greater detail the pattern of ingrowth of labeled retinal afferents ipsilateral (ipsi.) and contralateral (contra.) to an eye injection in Siamese fetuses of progressively older embryonic $(E)$ ages. The calibration bar $(0.3 \mathrm{~mm})$ applies to all ages. $A$, anterior $P$, posterior. Note that, at E32, ipsilateral label is largely confined to the optic tract, and it is not until $E 41(D)$ that a significant ipsilateral projection is present within the posterior pole (arrow) of the LGN.

of axons emerging from the retinae of normal and Siamese fetuses at these early stages of development is different. It is also possible that the time of arrival of retinal ganglion cell axons at the optic chiasm is an important determinant of their laterality. Consistent with this timing hypothesis is the observation in a number of different normally pigmented mammalian species that the uncrossed projection reaches the LGN at least one day later than the crossed projection (Lund and Bunt, 1976; So et al., 1978; Land and Lund, 1979; Linden et al., 1981; Shatz, 1983). In Siamese fetuses this delay in arrival of the ipsilateral fibers at the LGN appears to be even longer, by about 2 days (see Fig. 5). (However, Cucchiaro and Guillery (1984) found no difference in the time of arrival of ipsilateral retinal afferents at the LGN in albino and pigmented ferrets.) As mentioned by Bunt et al. (1983), an apparent delay may simply be due to limitations in the techniques employed: for example, it might not be possible to detect at the light microscope level a faint amount of ipsilateral label actually present earlier on as the first fibers grow out. Nevertheless, the level of detectability should remain the same in normal and albino animals if the same anterograde tracing methods are used, assuming that ipsilaterally projecting fibers in the mutant behave similarly with respect to uptake and transport of the tracers. If so, then, although the first fibers may not be detectable (either in normally pigmented or in Siamese cats using our methods), we can still assume that there is indeed a delay in the time it takes for a sufficient number of labeled fibers to reach detectable levels within the LGN of Siamese relative to normally pigmented cats. Unfortunately, however, without electron microscopic studies it is currently impossible to distinguish between a true delay in time of arrival of the ipsilateral projection at the LGN and an apparent delay which is due to the fact that axons actually arrive at the normal time but cannot be detected due to methodological limitations.

The apparent delay seen here is also to be expected assuming the abnormality present in the adult Siamese retina is initially expressed during fetal life: in adults, there is a temporalward displacement of the decussation line that separates retinal ganglion cells projecting contralaterally from those projecting ipsilaterally (Kirk, 1976: Stone et al., 1978a, b; Cooper and Pettigrew, 1979a, b; Leventhal, 1982; Murakami et al., 1982). Since both the genesis of retinal ganglion cells (Kliot and Shatz, 1982; Walsh et al., 1983) and the outgrowth of their axons (Silver and Sidman, 1980) proceed in a rough center-to-peripheral fashion, such a displacement of the decussation line away from the optic nerve head would be expected to delay the time at which a detectable number of retinal ganglion cell axons arrive at the ipsilateral LGN of Siamese fetuses, and this is exactly what we have observed.

Another possibility is that pigment may play a role in determining the laterality of retinal ganglion cell axons. It has long been known that an abnormal retinofugal projection is frequently associated with a reduction in adult levels of melanin within the retinal pigment epithelium in many mammalian species (Sanderson et al., 1974; Giolli and Creel, 1974; Creel and Giolli, 1972, 1976; Creel et al., 1978, 1982; LaVail et al., 1978; Guillery et al., 1979; Drager and Olsen, 1980; Thibios et al., 1980). We have reported (Shatz and Kliot, 1982) that a reduction in pigment levels is present within the retina of Siamese cats throughout fetal development, suggesting that actual pigment levels may control the laterality of retinal ganglion 

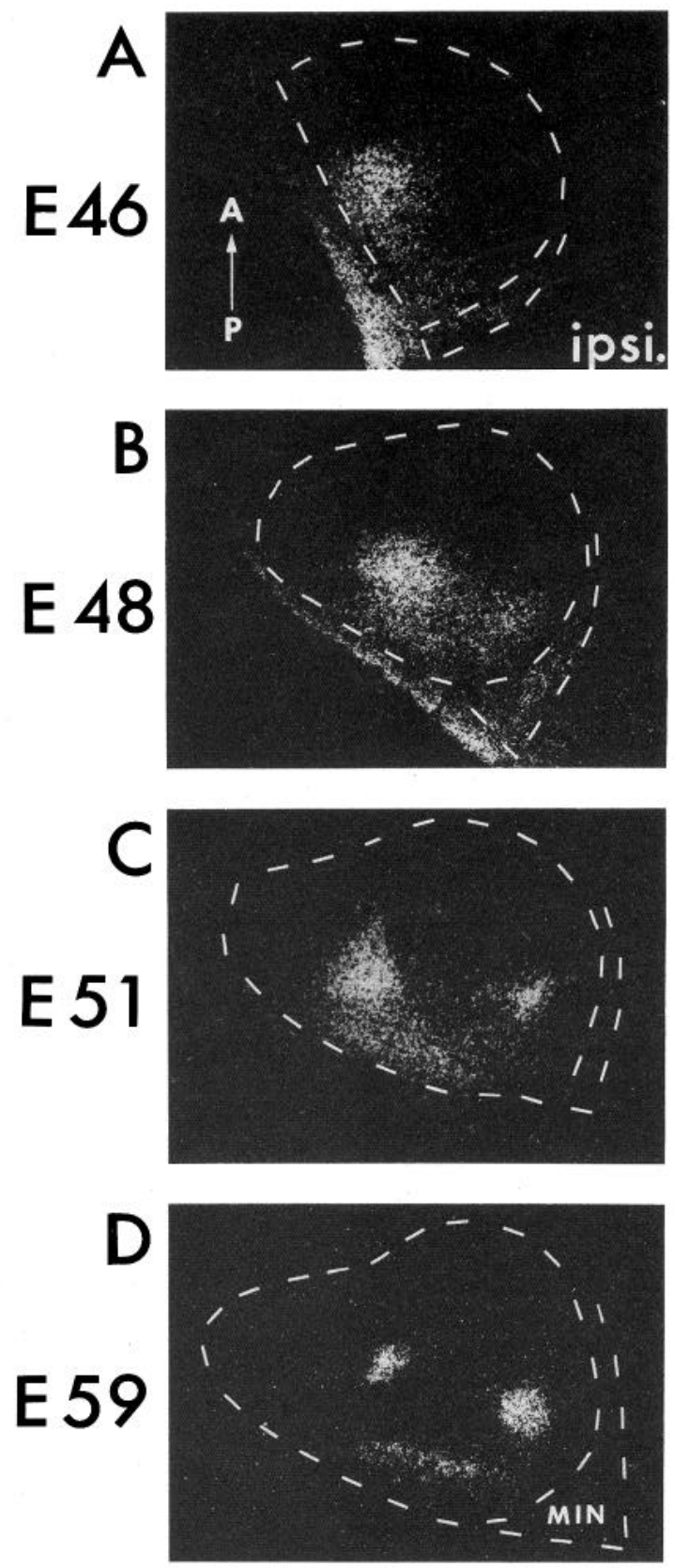
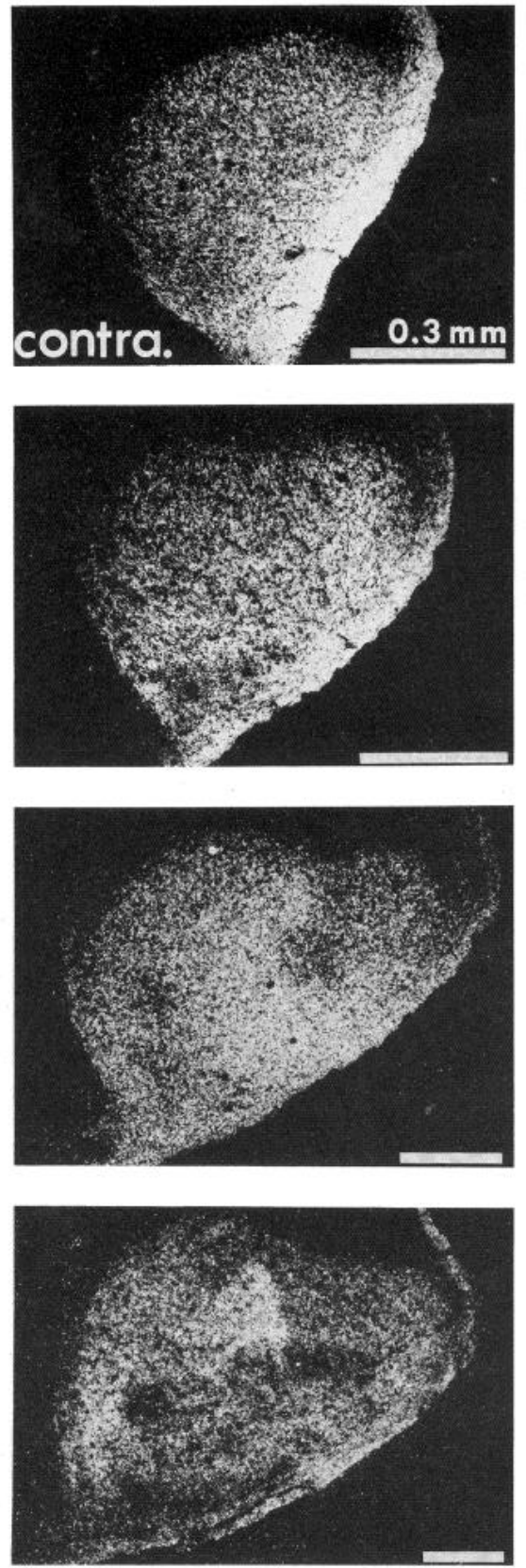

Figure 8. Darkfield autoradiographs of horizontal sections to show the pattern of radioactively labeled retinal afferents within the ipsilateral (ipsi.) and contralateral (contra.) LGN of Siamese fetuses at progres. sively older embryonic $(E)$ ages during the last third of gestation. At each age, a comparable section through the middle of the LGN has been selected. Ipsilateral LGN and medial interlaminar nucleus (MIN) are outlined by dashed lines. All calibration bars = $0.3 \mathrm{~mm}$. $A$, anterior; $P$, posterior. Note the gradual increase in labeling of the medial and lateral normal segments of layer A1 on the ipsilateral side, and the appearance of gaps in the corresponding regions on the contralateral side. cell axons. Consistent with this suggestion is the finding that within true albino cats, which have no retinal pigment at all, the ipsilateral projection is even more reduced than in Siamese cats (Creel et al., 1982).

Pigment in the optic stalk rather than within the retina could also be the causative factor. This consideration arises from the observation in several different mammalian species (Oberdorfer et al., 1981; Silver and Sapiro, 1981; Strongin and Guillery, 1981), including the cat (J. Silver, M. Kliot, and C. J. Shatz, manuscript in preparation), that portions of the distal optic stalk normally become transiently pigmented just prior to the arrival of the first retinal fibers. Albinos of these species, including Siamese fetuses, lack this pigmented region and show an alteration in the position of the first retinal fibers that grow into the optic stalk. In agreement with this finding, Murakami et al. (1982) have shown that retinal fibers within the optic disc of adult normal and Siamese cats differ in their arrangement. It is therefore possible that the position of a retinal ganglion cell axon within the developing optic nerve is an important determinant of whether or not it will cross at the optic chiasm. The finding that there is some degree of order found in the developing optic nerve of mammals (Silver and Sidman, 1980; Bunt and Horder, 1983; Silver, 1984) lends support to this idea.

Ingrowth and segregation of retinogeniculate afferents. The development of the Siamese cat's retinogeniculate projection shows the same general sequence of ingrowth and segregation as that seen in normally pigmented animals: partial intermixing between the afferents from both eyes is followed by segregation into separate regions of the nucleus (Fig. 11). However, based on our analysis, in Siamese fetuses ingrowth of the ipsilateral projection is both delayed and much more gradual than in normally pigmented fetuses, at least as indicated by the anterograde tracing methods used here: retinal afferents first invade the posterior pole of the ipsilateral LGN on E41 in Siamese fetuses as compared to E35 in normal fetuses (Fig. 10). We believe that these differences are due to the existence of a true delay in the time of arrival of afferents at the LGN and to the diminution in number of afferents from the ipsilateral eye. Despite these differences, it is noteworthy that the peak percentage of LGN territory occupied by the ipsilateral projection in Siamese fetuses 

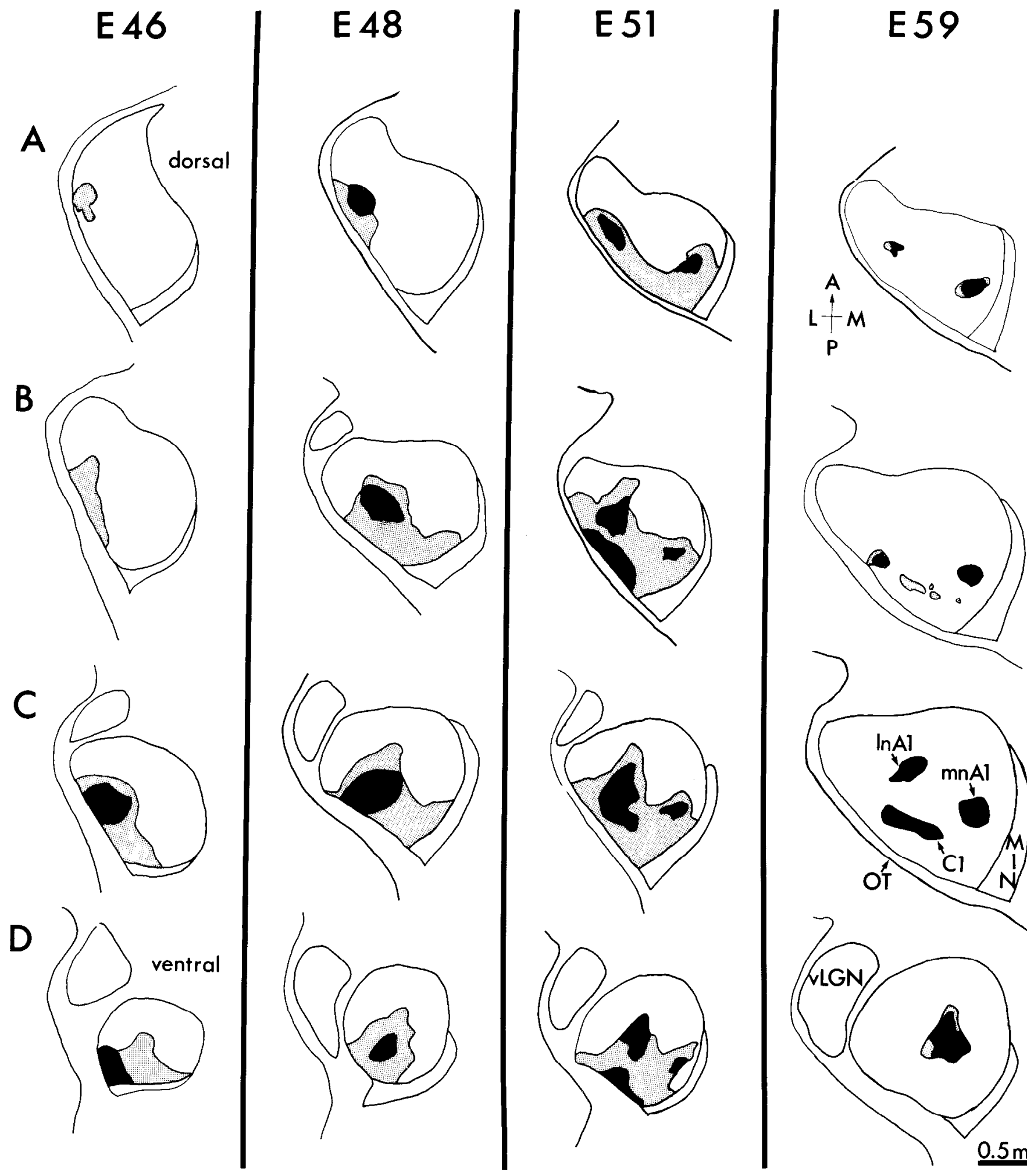

E59

Figure 9. A series of camera lucida drawings of horizontal sections taken at four different levels through the LGN in Siamese fetuses aged E46, E48, E51, and E59 to illustrate the change in the pattern of the ipsilateral projection. The top section $(A)$ in each column is the most dorsal one. Areas in black indicate heavily labeled regions; lightly labeled regions are gray. Note the progressive appearance of densely labeled patches with a corresponding decline in labeling within intervening regions at older ages. Some of the drawings here were made from the autoradiographs shown in Figure 8: E46C is from Figure $8 A, E 48 C$ is from Figure $8 B ; E 51 B$ is from Figure $8 C$; and $E 59 C$ is from Figure $8 D$. The calibration bar $(0.5 \mathrm{~mm})$ applies to all embryonic (E) ages, inA1 and $m n A 1$, lateral and medial normal segments of layer $A 1 ; C 1$, layer $C 1 ; M I N$, medial interlaminar nucleus; OT, optic tract; vLGN, ventral lateral geniculate nucleus; $A$, anterior; $P$, posterior; $L$, lateral; $M$, medial.

( $40 \%$ at E51) approaches the value seen in normal fetuses $(48 \%$ at E47). One explanation for this observation is that, even though the ipsilateral projection is diminished, individual axons arborize more extensively than normal. However, this suggestion is not consistent with the observation that the density of labeling is much patchier than normal (Figs. $8 C$ and 9, E51), suggesting that axons do not compensate by making excessive arbors. Nevertheless, label occupies approximately the same territory at E51 as normal, suggesting 


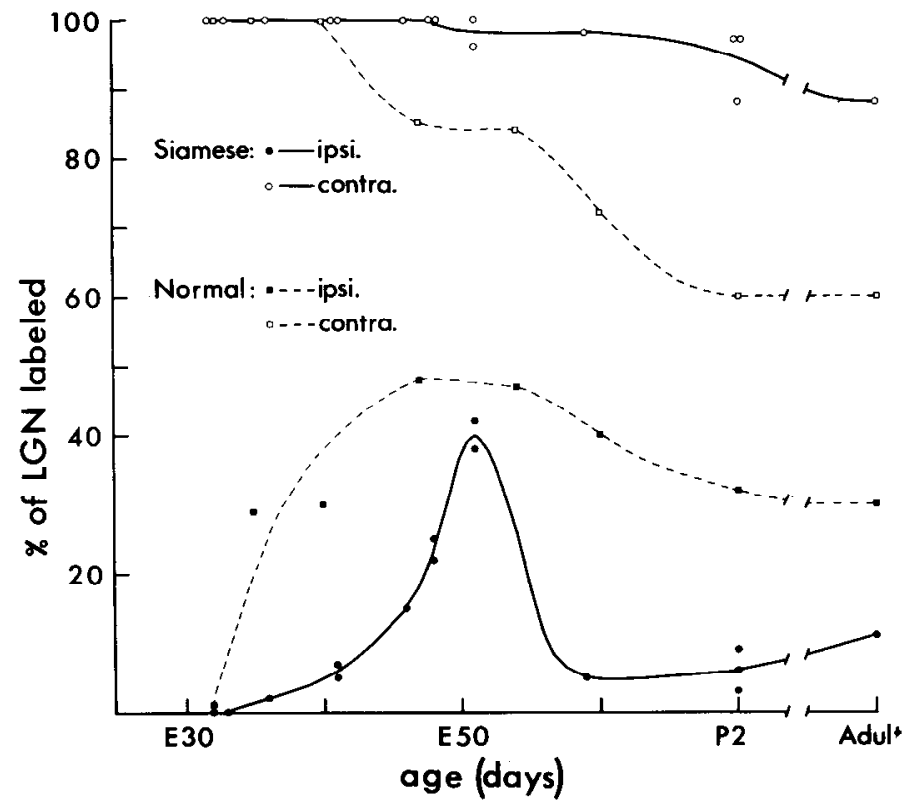

Figure 10. Graphs to compare the progressive changes with age in the percentage of LGN area occupied by labeled retinal afferents from the ipsilateral (ipsi.- - solid symbols) and contralateral (contra. - open symbols) eyes in Siamese (circles) and normal (squares) animals. Values for normal animals are the average at each age taken from a previous study (Shatz, 1983). Curves for Siamese (solid lines) and normal (dashed lines) animals were drawn by eye. See "Materials and Methods" for more detail. Note that the time course of development of the retinogeniculate projection and the percentage of area of the nucleus occupied by the afferents is significantly different in Siamese cats.

that, although there is a reduction in fiber number, many fibers may still project to their topographically appropriate sites at this age. If so, then the fetal projection may resemble that found in adult Siamese cats in which the ipsilateral retinogeniculate projection arises from a diminished number of retinal ganglion cells that are nevertheless distributed as in normal cats throughout the entire temporal half of the retina (Kirk, 1976; Cooper and Pettigrew, 1979a, b; lling and Wassle, 1981; Leventhal, 1982).

The formation of the segregated paltern in Siamese cals involves several steps, the first of which is the appearance of a condensed patch of label in the lateral portion of future layer A1. In adult Siamese cats the lateral normal segment of $A 1$ receives input from the peripheral portion of the temporal retina (Guillery and Kaas, 1971). This portion of the temporal retina is known to supply the highest percentage of retinal ganglion cells projecting ipsilaterally (Cooper and Pettigrew, 1979b, Fig. 14). Thus, the high density of label seen in the future lateral normal segment of developing layer A1 by E46 (Fig. $8 A$ ) suggests that the set of ipsilaterally projecting retinal ganglion cell axons may be topographically arranged by then. This suggestion is consistent with the observation that the majority of retinal ganglion cells throughout the retina are generated by E35 (Kliot and Shatz, 1982; Walsh et al., 1983) and, therefore, those from the peripheral retina would have had sufficient time to reach and grow into the LGN.

It is not until several days later, on E51, that the beginnings of the medial normal segment of layer A1 are first signaled by the appearance of a dense zone of label in the medial portion of the LGN and the concurrent reduction in label in regions intervening between the lateral and medial normal segments (cf. Figs. 8 and 9). The appearance of the medial normal segment, as well as the lateral normal segment, may be due in part to the progressive growth and elaboration of axonal arborizations in a manner similar to that found to occur during normal development (Sretavan and Shatz, 1984). Alternatively, both segments could arise from the redistribution of axon terminal arbors displaced from intervening regions. In this context, it is worth noting that, in the LGN of normal animals, axons may be able to alter their course and the location of their terminal arborizations only after E50. Sludies in which oplic tract axons have been filled with HRP at different fetal ages have demonstrated that, prior to E50, all axons traverse the nucleus to their termination sites in straight trajectories, and it is only later on that axons with abrupt alterations in their course through the nucleus can be detected (D. W. Sretavan and C. J. Shatz, manuscript in preparation). If such alterations are indeed related to the redistribution of terminal arbors, then redistributions in Siamese cats might be expected to result in a compression of retinal topography-an expectation consistent with anatomical (Cooper and Pettigrew, 1979b) and physiological (Guillery and Kaas, 1973) evidence that retinal ganglion cells throughout the entire temporal retina of adult Siamese cats project upon a reduced portion of the $A 1$ layer: the medial and lateral normal segments.

Displacement of axons or their terminals might also account for the loss of label from intervening regions that is almost completc by E59 (Figs. 8 and 9). Another possibility is that the reduction may be due to an actual elimination of axons that project to the intervening regions. This possibility is consistent with the observation that, during this developmental period in normal animals, a massive elimination of axons occurs within the optic nerve ( $\mathrm{Ng}$ and Stone, 1982; Williams et al., 1983). At present, we cannot distinguish between any of the alternatives outlined above and, in fact, we would expect all to contribute to some extent to the establishment of the adult pattern of projection.

The appearance of the lateral and medial normal segments on the ipsilateral side by $\mathrm{E} 51$ is correlated with the appearance of corresponding gaps on the contralateral side, signaling the onset of segregation. In contrast, the segregation of retinal afterents is tirst evident in normal fetuses at E47 (Shatz, 1983), indicating that in Siamese fetuses the onset of segregation is delayed several days. This delay may arise as a consequence of the similar delay in the arrival and ingrowth of ipsilateral fibers. It may also indicate that a "critical density" of ipsilateral fibers must be achieved in order to trigger the segregation process. This suggestion is consistent, on the one hand, with the finding that prenatal enucleation blocks segregation of input from the remaining eye (Rakic, 1981; Williams and Chalupa, 1983) and, on the other hand, with the finding that segregation of eye input is produced in the presence of a supernumerary eye (Constantine-Paton and Law, 1978).

Not only is the pattern of retinal afferent ingrowth and segregation within the LGN abnormal, but also the establishment of cellular

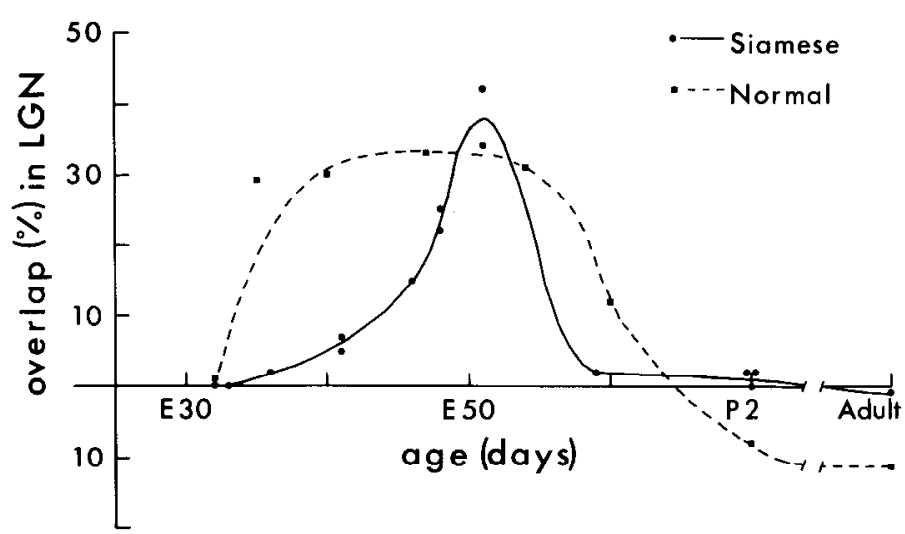

Figure 11. Graphs to compare the progressive changes with age in the percentage of LGN shared by retinal afferents from the two eyes (overlap percentage) in Siamese (solid circles and curve) and normal (solid squares and dashed curve) animals. The overlap percentage was calculated by adding together the percentage of area occupied by ipsilateral and contralateral afferents (from Fig. 10) for each animal and then subtracting $100 \%$. Negative overlap values indicate that portions of the nucleus are free of input from both eyes. Values for normal animals are the average at each age from a previous study (Shatz, 1983). Curves were drawn by eye. Note that the duration of overlap is greatly reduced in Siamese cats but that the peak overlap value is similar to that found in normal animals. 
lamination at birth is disrupted in Siamese cats (Fig. 4): the medial portions of the A and A1 layers are never separaled by an interlarminar zone. Prenatal enucleation experiments in both the cat (Williams and Chalupa, 1983) and ferret (Guillery et al., 1985) have shown that cellular lamination is, at least in part, dependent on the segregation of retinal afferents within the LGN. The abnormal and delayed appearance of cellular lamination within the Siamese LGN may therefore be a consequence of the delayed and altered segregation of retinal afferents seen in Siamese development.

Relation to normal development. The results of this study allow us to propose a series of events that give rise to the abnormal pattern of the retinogeniculate projection seen in adult Siamese cats. We have shown that the albino gene acts at or before the level of the optic chiasm to misdirect growing retinal ganglion cell axons to the contralateral side. This misrouting leads to a delay in the arrival and ingrowth of ipsilateral retinal fibers to the LGN. Consequently, there is a delay in the segregation of retinal afferents and in the appearance of cellular lamination, both of which differ from the normal pattern throughout development.

This proposed sequence of events has a number of important implications for normal development. One is that the final pattern of the retinogeniculate projection may depend on the relative balance of inputs from the two eyes. A second is that the time course of segregation may be influenced by the time of arrival of the ipsilateral retinal afferents. Thus, input from the periphery may play an important role in determining the pattern of connectivity present at more central levels of the visual system.

\section{References}

Bunt, S. M., and T. J. Horder (1983) Evidence for an orderly arrangement of optic axons within the optic nerves of the major nonmammalian vertebrate classes. J. Comp. Neurol. 213: 94-114.

Bunt, S., R. D. Lund, and P. W. Land (1983) Prenatal development of the optic projection in albino and hooded rats. Dev. Brain Res. 6: 149-168.

Constantine-Paton, M., and M. I. Law (1978) Eye-specific termination bands in tecta of three-eyed frogs. Science 202: 639-641.

Cooper, M. L., and J. D. Pettigrew (1979a) The decussation pathway in the cat, with a note on the major meridians of the cat's eye. J. Comp. Neurol. 187: 285-312.

Cooper, M. L., and J. D. Pettigrew (1979b) The retinothalamic pathways in Siamese cats. J. Comp. Neurol. 187: 313-348

Creel, D. J., and R. A. Giolli (1972) Retinogeniculostriate projections in guinea pigs: Albino and pigmented strains compared. Exp. Neurol. 36: 411-425

Creel, D., and R. A. Giolli (1976) Retinogeniculate projections in albino and ocularly hypopigmented rats. J. Comp. Neurol. 166: 445-456.

Creel, D., F. E. O'Donnell, and C. J. Witkop (1978) Visual system anomalies in human ocular albinos. Science 201: 931-933.

Creel, D., A. E. Hendrickson, and A. G. Leventhal (1982) Retinal projections in tyrosinase-negative albino cats. J. Neurosci. 2: 907-911.

Cucchiaro, J., and R. W. Guillery (1984) The development of the retinogeniculate pathways in normal and albino ferrets. Proc. R. Soc. Lond. (Biol.) 223: $141-164$.

Drager, U. C., and J. F. Olsen (1980) Origins of crossed and uncrossed retinal projections in pigmented and albino mice. J. Comp. Neurol. 191: 383-412.

Giolli, R. A., and D. J. Creel (1974) Inheritance and variability of the organization of the retinogeniculate projections in pigmented and albino rats. Brain Res. 78: 335-339.

Guillery, R. W. (1969) An abnormal retinogeniculate projection in Siamese cats. Brain Res. 14: 739-741.

Guillery, R. W. (1970) The laminar distribution of retinal fibers in the dorsal lateral geniculate nucleus of the cat: A new interpretation. J. Comp. Neurol. 138: $339-368$

Guillery, R. W. (1971) An abnormal retinogeniculate projection in the albino ferret (Mustela furo). Brain Res. 33: 482-485.

Gullery, R. W., and J. H. Kaas (1971) A study of normal and congenitally abnormal retinogeniculate projections in cats. J. Comp. Neurol. 143: 73100.

Guillery, R. W., and J. H. Kaas (1973) Genetic abnormality of the visual pathways in a 'white' tiger. Science 180: 1287-1289.

Guillery, R. W., G. L. Scott, B. M. Cattanach, and M. S. Deol (1973) Genetic mechanisms determining the central visual pathways of mice. Science 179: 1014-1016.

Guillery, R. W., A. N. Okoro, and C. J. Witkop (1975) Abnormal visual pathways in the brain of a human albino. Brain Res. 96: 373-377.

Guillery, R. W. M. D. Oberdorfer, and E. H. Murphy (1979) Abnormal retinogeniculate and geniculo-cortical pathways in several genetically distinct color phases of the mink. J. Comp. Neurol. 185: 623-656.

Guillery, R. W., T. L. Hickey, J. H. Kaas, D. J. Felleman, E. J. Debruyn, and D. L. Sparks (1984) Abnormal central visual pathways in the brain of an albino Green monkey (Cercopithecus aethiops). J. Comp. Neurol. 226. $165-183$.

Guillery, R. W., A. S. LaMantia, J. A. Robson, and K. Huang (1985) The influence of retinal afferents upon the development of layers on the dorsal lateral geniculate nucleus of mustelids. J. Neurosci. 5: 1370-1379.

Hickey, T. L., and R. W. Guillery (1974) An autoradiographic study of geniculate pathways in the cat and fox. J. Comp. Neurol. 156: 239-253.

Illing, R. -B., and H. Wassle (1981) The retinal projection to the thalamus in the cat: A quantitative investigation and a comparison with the retinotectal pathway. J. Comp. Neurol. 202: 265-285.

Kaas, J. H., and R. W. Guillery (1973) The transfer of abnormal visual field representations from the dorsal lateral geniculate nucleus to the visual cortex in Siamese cats. Brain Res. 59: 61-95.

Kalil, R. (1978) Development of the dorsal lateral geniculate nucleus in the cat. J. Comp. Neurol. 182: 265-292.

Kirk, D. L. (1976) Projections of the visual field by the axons of cat retinal ganglion cells. Section 2. Decussation of optic axons in Siamese cats. Ph.D. thesis, Australian National University, Canberra, Australia.

Kliot, M., and C. J. Shatz (1982) Genesis of different retinal ganglion cell types in the cat. Soc. Neurosci. Abstr. 8: 815

Land, P. W., and R. D. Lund (1979) Development of the rat's uncrossed retinotectal pathway and its relation to plasticity studies. Science 205 . $698-700$.

Land, P. W., K. Hargrove, J. Eldridge, and R. D. Lund (1981) Differential reduction in the number of ipsilaterally projecting ganglion cells during the development of retinofugal projections in albino and pigmented rats. Soc. Neurosci. Abstr. 7: 141

LaVail, J. H., R. A. Nixon, and R. L. Sidman (1978) Genetic control of retinal ganglion cell projections. J. Comp. Neurol. 182: 399-422.

Leventhal, A. G. (1982) Morphology and distribution of retinal ganglion cells projecting to different layers of the dorsal lateral geniculate nucleus in normal and Siamese cats. J. Neurosci. 2: 1024-1042.

Lia, B., R. W. Williams, and L. M. Chalupa (1983) Early development of retinal specialization: The distribution and decussation pattern of ganglion cells in the prenatal cat demonstrated by retrograde peroxidase labeling. Soc. Neurosci. Abstr. 9: 702

Linden, D. C., R. W. Guillery, and J. Cucchiaro (1981) The dorsal lateral geniculate of the normal ferret and its postnatal development. J. Comp. Neurol. 203: 189-211.

Lund, R. D. (1965) Uncrossed visual pathways of hooded and albino rats Science 149: 1506-1507.

Lund, R. D., and A. H. Bunt (1976) Prenatal development of central optic pathways in albíno rats. J. Comp. Neurol. 165: 247-264

Mesulam, M. M. (1976) The blue reaction product in horseradish peroxidase neurohistochemistry: Incubation parameters and visibility. J. Histochem. Cytochem. 24: 1273-1280

Murakami, D., M. A. Sesma, and M. H. Rowe (1982) Characteristics of nasal and temporal retina in Siamese and normally pigmented cats: Ganglion cell projection, axon trajectory and laterality of projection. Brain Behav. Evol. 21: 67-113.

$\mathrm{Ng}, \mathrm{A} . \mathrm{Y} . \mathrm{K}_{\mathrm{.}}$ and J. Stone (1982) The optic nerve of the cat: Appearance and loss of axons during normal development. Dev. Brain Res. 5: 263271.

Oberdorfer, M. D., N. Miller, and J. Silver (1981) Distribution of axons in albino and pigmented embryonic optic stalks. Invest. Ophthalmol. Vis. Sci. 20: 174.

Rakic, P. (1976) Prenatal genesis of connections subserving ocular dominance in the rhesus monkey. Nature 261: 467-471.

Rakic, P. (1981) Development of visual centers in the primate brain depends on binocular competition before birth. Science 214: 928-931.

Sanderson, K. J., R. W. Guillery, and R. M. Shackelford (1974) Congenitally abnormal visual pathways in mink with reduced retinal pigment. J. Comp. Neurol. 154: 225-245

Shatz, C. (1977) A comparison of visual pathways in Boston and Midwestern Siamese cats. J. Comp. Neurol. 171: 205-228.

Shatz, C. J. (1983) The prenatal development of the cat's retinogeniculate 
pathway. J. Neurosci. 3: 482-499.

Shatz, C. J., and M. Kliot (1982) Prenatal misrouting of the retinogeniculate pathway in Siamese cats. Nature 300: 525-529.

Silver, J. (1984) Studies on the factors that govern directionality of axonal growth in the embryonic optic nerve and at the optic chiasm of mice. $J$ Comp. Neurol. 223: 238-251.

Silver, J., and J. Sapiro (1981) Axonal guidance during development of the optic nerve: The role of pigmented epithelia and other extrinsic factors. J. Comp. Neurol. 202: 521-538

Silver, J., and R. C. Sidman (1980) A mechanism for the guidance and topographic patterning of retinal ganglion cell axons. J. Comp. Neurol 189: 101-111.

So, K. F., G. E. Schneider, and D. O. Frost (1978) Postnatal development of retinal projections to the lateral geniculate body in Syrian hamsters. Brain Res. 142: 343-352.

Sretavan, D. W., and C. J. Shatz (1984) Prenatal development of individual retinogeniculate axons during the period of segregation. Nature 308: $845-$ 848

Stent, G. S. (1981) Strength and weakness of the genetic approach to the development of the nervous system. Annu. Rev. Neurosci. 4: 163-194.

Stone, J., M. H. Rowe, and J. E. Campion (1978a) Retinal abnormalities in the Siamese cat. J. Comp. Neurol. 180: 773-782.

Stone, J., J. E. Campion, and J. Leicester (1978b) The nasotemporal division of retina in the Siamese cat. J. Comp. Neurol. 180: 783-798.

Strongin, A. C., and R. W. Guillery (1981) The distribution of melanin in the developing optic stalk and its relation to cellular degeneration. J. Neurosci. 1: 1193-1204.

Thibios, L. N., W. R. Levick, and R. Morstyn (1980) Ocular pigmentation in white and Siamese cats. Invest. Ophthalmol. Vis. Sci. 19: 475-486.

Walsh, C., E. H. Polley, T. L. Hickey, and R. W. Guillery (1983) Generation of cat's retinal ganglion cells in relation to central pathways. Nature 302 : 611-614.

Williams, R. W., and L. M. Chalupa (1983) Expanded retinogeniculate projections in the cat following prenatal unilateral enucleation: Functional and anatomical analysis of an anomalous input. Soc. Neurosci. Abstr. 9: 701.

Williams, R. W., M. J. Bastiani, and L. M. Chalupa (1983) Loss of axons in the cat optic nerve following fetal unilateral enucleation: An electron microscopic analysis. J. Neurosci. 3: 133-144. 